\title{
MULTIPLE-PREGNANCY COMPLICATIONS
}

\author{
H. SKALBA, R. OSUCH-JACZEWSKA, O. LEMPART, Z. OCHABSKA \\ Department of Obstetrics and Gynecology, Silesian Academy of Medicine, Bytom, Poland
}

The material covers 332 twin pregnancies (including 5 of triplets) of which 208 (62.7\%) were premature deliveries and $124(37.3 \%)$ deliveries at term.

Of the twin pregnancies included in the group examined $15.7 \%$ developed complications (gestosis and eclampsia, kidney and beart diseases, anemia, bydramnios). Spontaneous deliveries were $66.7 \%$, operative deliveries $33.3 \%$. A bigh mortality of the second twin $(13.1 \%)$ is noticeable and it increases to $21.4 \%$ when operative procedures are applied to the first twin.

Multiple pregnancy presents serious problems of obstetric and social nature, due to difficulties connected with early diagnosis, predisposition to pregnancy and delivery complications, and a fivefold neonatal mortality among the newborns (Carston 1957, Guttmacher and Kohl 1958, Aaron et al. 1961, Graves et al. 1962, Kuczynski and Slomko 1965). According to Hellin's theory twin pregnancy occurs once every 89 deliveries and twice as often in parents born from twins. The rate of multiple pregnancies is markedly different in various countries: $1.4-1.5 \%$ in Poland, $1.4-1.6 \%$ in Sweden, $1.2 \%$ in France and Italy, $0.7 \%$ in Japan. In our material it was $1.26 \%$ (Carston 1957, Aaron et al. 1961, Graves et al. 1962, Spurway 1962, Kuczynski and Slomko 1965, Slomko and Kuczynski 1965a).

The purpose of this study is to find out, by means of clinical and statistical analysis, the frequency of pregnancy and delivery complications occurring in multiple pregnancies, and to determine the factors responsible for the destiny of the twin fetus, as well as to evaluate the indications for obstetric operations and the effects of the control of twin delivery.

Our material covers 332 twin pregnancies (including 5 of triplets) corresponding to $1.26 \%$ of the 26,316 deliveries occurred from 1962 to 1972 in the II Clinic of Obstetrics and Gynecology of the Silesian Academy of Medicine in Bytom.

The analysis concerned course of pregnancy, delivery, method of childbirth. The duration of delivery, the delay between the birth of the first and of the second fetus results from an examination of the clinical conditions of the newborns and their evaluation on the basis of the Apgar score, and, in case of death, from anatomo-pathological control.

\section{RESULTS}

Of the above 332 twin pregnancies, $208(62.7 \%)$ resulted into premature deliveries and $124(37.3 \%)$ into at term deliveries (Table 1). Of the twin pregnancies examined $15.7 \%$ 
Table 1. Twin Deliveries and Time of Gestation

Weeks of pregnancy

Twin deliveries $(\mathrm{N}=332)$

$\mathrm{N} \%$

Untimely and premature deliveries

$\mathrm{Up}$ to 28

28-29

$30-32$

$33-35$

$36-38$

25 (1 triplet) $\quad 7.5$

12 (1 triplet) $\quad 3.6$

$24 \quad 7.2$

60 (1 triplet) $\quad 18.0$

87 (1 triplet) 26.2

Total

208

62.7

On time and postmature deliveries 39-41

42 and more

$51 \quad 15.3$

73 (1 triplet) 22.0

Total

124

37.3

exhibited pregnancy complications, the most serious being gestosis and eclampsia, kidney and heart diseases, anemia, hydramnios and other (Table 2). Table 3 shows the kind of fetus positions, the course and kind of delivery, as well as newborn deaths with reference to the above mentioned factors. Spontaneous deliveries were $66.7 \%$ while operative deliveries, owing to irregular presentation of the fetus, were $33.3 \%$. A high mortality of the second twin $(13.1 \%$ ) is noticeable, and it further increases to $21.4 \%$ when operative measures are applied to the first twin, the latter's mortality being $7.7 \%$ and

Table 2. Pregnancy Complications

\begin{tabular}{lrr}
\hline \hline & $N$ & $\%$ \\
Pregnancy & 280 & 84.3 \\
Uncomplicated & 52 & 15.7 \\
Complicated & 8 & \\
\hline Gestosis & 3 & \\
Eclampsia & 7 & \\
Kidney diseases & 4 & \\
Hypertension & 5 & \\
Heart diseases & 4 & \\
Bleeding & 6 & \\
Anemia & 3 & \\
Prolonged gestation & 4 & \\
Epidemic jaundice & 3 & \\
Infections & 5 & \\
Hydramnios & 332 & \\
\hline Total & 100.0 \\
\hline
\end{tabular}


Table 3. Perinatal Mortality and Kind of Delivery in Twins

\begin{tabular}{|c|c|c|c|c|c|c|c|c|c|c|c|c|}
\hline \multirow{3}{*}{ Kind of delivery } & \multicolumn{4}{|c|}{ Twin I } & \multicolumn{4}{|c|}{ Twin II } & \multicolumn{4}{|c|}{ Both twins } \\
\hline & \multirow[b]{2}{*}{$\mathrm{N}$} & \multirow[b]{2}{*}{$\%$} & \multicolumn{2}{|c|}{ Deaths } & \multirow[b]{2}{*}{$\mathrm{N}$} & \multirow[b]{2}{*}{$\%$} & \multicolumn{2}{|c|}{ Deaths } & \multirow[b]{2}{*}{$\mathrm{N}$} & \multirow[b]{2}{*}{$\%$} & \multicolumn{2}{|c|}{ Deaths } \\
\hline & & & $\bar{N}$ & $\%$ & & & $\overline{\mathrm{N}}$ & $\%$ & & & $\bar{N}$ & $\%$ \\
\hline Spontaneous & 237 & & 17 & 7.2 & 209 & & 17 & 8.1 & 446 & 66.7 & 34 & 7.2 \\
\hline $\begin{array}{l}\text { Head } \\
\text { Breech } \\
\text { Breech } \\
\text { Legs } \\
\text { Face }\end{array}$ & & & & & & & & & $\begin{array}{r}240 \\
206 \\
188 \\
16 \\
2\end{array}$ & $\begin{array}{l}35.9 \\
30.8\end{array}$ & & \\
\hline Operative & 97 & 43.5 & 9 & 9.3 & 126 & 56.5 & 27 & 21.4 & 223 & 33.3 & 36 & 16.1 \\
\hline $\begin{array}{l}\text { Manual aid by Bracht } \\
\text { method and classical } \\
\text { Extraction of fetus } \\
\text { by hand } \\
\text { Internal rotation } \\
\text { and hand extraction } \\
\text { Cephalotractor } \\
\text { Cesarotomy }\end{array}$ & & & & & & & & & $\begin{array}{r}188 \\
4 \\
12 \\
9 \\
10\end{array}$ & & & \\
\hline Total & 334 & & 26 & 7.7 & 335 & & 44 & 13.1 & 669 & 100.0 & 70 & 10.5 \\
\hline
\end{tabular}

rising to $9.3 \%$ after operative treatment. Table 4 shows the deaths of the newborns within particular weight groups (newborns under $1000 \mathrm{~g}$ have been excluded from the analysis). The death rate of newborns with low birth-weight accounts for $15.7 \%$, and it rises as the weight of the fetus decreases from $1500 \mathrm{~g}$ down. Deaths of full-term newborns were reported in $1.6 \%$ of cases.

\section{DISCUSSION}

Frequency of twin pregnancies in our material is $1.26 \%$ out of 26,316 deliveries investigated during the same period. Such figures are in agreement with the reports of other authors (Carston 1957, Aaron et al. 1961, Graves et al. 1962, Potter 1963, Kuczynski and Slomko 1965, Slomko and Kuczynski 1965a, Sternadel 1967d).

According to literature data, the rate of pregnancy and delivery complications is up to 40 times higher in multiple pregnancy as compared to the single one. In our investigations we found $15.7 \%$ serious complications of pregnancies and $33.3 \%$ deliveries by means of obstetrical measures; for the first twin we found $43.5 \%$, for the second one $56.5 \%$, due to his frequent irregular presentation $(69.3 \%$ of cases). Similar results were found by Ware and others, who reported an irregular presentation of the first twin in $28 \%$ of cases, and of the second one in 46.9\% (Guttmacher and Kohl 1958, Kuczynski and Slom- 
Table 4. Neonatal Mortality and Birth Weight

\begin{tabular}{lllll}
\hline \hline Birth weight (g) & $\mathrm{N}$ & $\%$ & $\frac{\text { Deaths }}{\mathrm{N}}$ & $\%$ \\
\hline Up to 1000 & 51 & 7.6 & 49 & 96.1 \\
\hline
\end{tabular}

\begin{tabular}{lrrrr} 
Newborns with low birth weight & & & \\
$1001-1250$ & 25 & 3.7 & 15 & 60.0 \\
$1251-1500$ & 48 & 7.2 & 27 & 56.2 \\
$1501-2000$ & 121 & 18.1 & 22 & 18.2 \\
$2001-2250$ & 175 & 26.2 & 2 & 1.1 \\
Total & 420 & 62.8 & 66 & 15.7 \\
\hline- & & & & \\
Mature newborns & 102 & 15.2 & 4 & 3.9 \\
$2251-2500$ & 147 & 22.0 & - & \\
Over 2500 & 249 & 37.2 & 4 & 1.6 \\
Total & & & & \\
& & & & \\
\hline
\end{tabular}

ko 1965, Sternadel 1967d, Ware 1971). A crucial problem in multiple pregnancy is that of premature delivery, which occurs in not less than $62.7 \%$ of pregnancies below the 38th week. Along with complications associated to pregnancy and delivery, and with low weight, this carries a further hazard to the fetus.

Guttmacher and others in their own material found $50-52 \%$ of premature deliveries, i.e., a rate eight times higher than in all pregnant women (Guttmacher and Kohl 1958, Slomko and Kuczynski 1965a). As a result, and according to the recommendations of WHO (1970) every case of multiple pregnancy was hospitalized in order to reduce the number of premature deliveries and allow for stimulation of the activity of the womb by means of shrinking drugs, as well as to eliminate prolonged deliveries (generally lasting 5-8 hours). The time interval between delivery of the first fetus and delivery of the second one should be within optimal limits from 15 to 25 minutes. There is no agreement in the literature as to optimal duration for the delivery of the second twin.

Carston (1957) suggests that the time limit should not exceed 15 minutes; Weddel et al. (1960), 6-10; and Graves et al. (1962), 15-20. We found no difference in either pregnancy or delivery as concerns parity and maternal age. Some authors quote a higher mortality of fetuses and newborns among primiparae (Guttmacher and Kohl 1958, Sternadel 1967d). Perinatal mortality of twins is reported to be $10.6-16.6 \%$ and the mortality of the second twin 4-5\% higher (Carston 1957, Spurway 1962, Slomko and Kuczynski 1965a, Ware 1971). Of a total of 669 twins studied, the mortality of the newborn is $10.5 \%$, while the mortality of the second twin is $13 \%$ and in operative deliveries it rises up to $21 \%$. 
It may be concluded that early hospitalization in cases of multiple pregnancy - from the 28th week of pregnancy on, in compliance with the WHO's recommendations (1970) may contribute to improve early diagnosis and reduce the number of premature deliveries, which in turn shall decrease the incidence of neonatal mortality.

Henryk Skalba, M.D., ul. Dworcowa, Bytom, Poland. 